\title{
Superconductivity and magnetism of the $\mathrm{R}_{6} \mathrm{Ni}_{2} \mathrm{Sn}$ $(\mathrm{R}=\mathrm{Y}$ and rare earth) compounds
}

\author{
J.W. Chen ${ }^{\mathrm{a}, *}$, N.S. Jou ${ }^{\mathrm{a}}$, B.K. Wang ${ }^{\mathrm{a}}$, Ching-Ray Chang ${ }^{\mathrm{a}}$, R.C. Yang ${ }^{\mathrm{a}}$, \\ Y.Y. Chen ${ }^{b}$ \\ a Department of Physics, National Taiwan University, Taipei, Taiwan, ROC \\ ${ }^{\mathrm{b}}$ Institute of Physics, Academia Senica, Taipei, Taiwan, ROC
}

\begin{abstract}
We have performed AC electrical resistivity $\rho$, DC magnetic susceptibility $\chi_{\mathrm{DC}}$ and heat capacity $C(T)$ measurements on the ternary compounds $\mathrm{R}_{6} \mathrm{Ni}_{2} \mathrm{Sn}\left(\mathrm{R}=\mathrm{Y}\right.$ and rare earth). Our results show that $\mathrm{La}_{6} \mathrm{Ni}_{2} \mathrm{Sn}$ becomes superconducting with $T_{\mathrm{c}} \sim 2.3 \mathrm{~K}$. Except for $\mathrm{R}=\mathrm{Y}, \mathrm{Ce}$, and $\mathrm{Pr}$, most of the $\mathrm{R}_{6} \mathrm{Ni}_{2} \mathrm{Sn}$ compounds undergo various magnetic transitions as revealed from the appearance of features in both $\chi(T)$ and $C(T)$ curves, and changes of the slopes in the $\rho(T)$ curves. $\mathrm{Ce}_{6} \mathrm{Ni}_{2} \mathrm{Sn}$ is a heavy fermion compound with its specific heat $C / T$ increases logarithmically for $1 \mathrm{~K}<T<7 \mathrm{~K}$ and reaches a value of $\sim 160 \mathrm{~mJ} / \mathrm{mol} \mathrm{Ce}-\mathrm{K}^{2}$ at $0.35 \mathrm{~K}$.
\end{abstract}

(C) 2005 Elsevier B.V. All rights reserved.

PACS: $71.27+\mathrm{a} ; 74.25 . \mathrm{Fy} ; 75.30 . \mathrm{Cr}$

Keywords: Superconductivity; Magnetic transition; Heavy fermion

The $\mathrm{R}_{6} \mathrm{Ni}_{2} \mathrm{Sn} \quad(\mathrm{R}=$ rare earth $)$ compounds belong to the $\mathrm{Ho}_{6} \mathrm{Ni}_{2} \mathrm{Ga}$-type structure with space group Immm [1]. Among them, $\mathrm{Er}_{6} \mathrm{Ni}_{2} \mathrm{Sn}$ has been mostly studied because of its usage for the magnetic refrigeration [2,3]. Recent study reveals that $\mathrm{La}_{6} \mathrm{Ni}_{2} \mathrm{Sn}$ is a type-II superconductor with a transition temperature $T_{\mathrm{c}}$ of $2.25 \mathrm{~K}$ [4]. To have further understanding about these compounds, we

\footnotetext{
*Corresponding author. Tel.: +886233665172; fax: +886223639984 .

E-mail address: jwchen@phys.ntu.edu.tw (J.W. Chen).
}

have studied the transport, magnetic, and specific heat properties of these systems.

Polycrystalline samples of $\mathrm{R}_{6} \mathrm{Ni}_{2} \mathrm{Sn}(\mathrm{R}=\mathrm{Y}$ and rare earth) were prepared by arc-melting stochiometric amounts of the constituent elements (R: 99.99\%, Ni: $99.99 \%$, Sn: $99.9999 \%$ ) together on a water-cooled copper hearth in a Zr-gettered argon atmosphere. The as-melted samples were subsequently wrapped in Ta foil, sealed in quartz tube in argon atmosphere, and annealed at $550{ }^{\circ} \mathrm{C}$ for 3 days. AC electrical resistivity of bar-shaped samples has been measured in a ${ }^{4} \mathrm{He}$ cryostat 

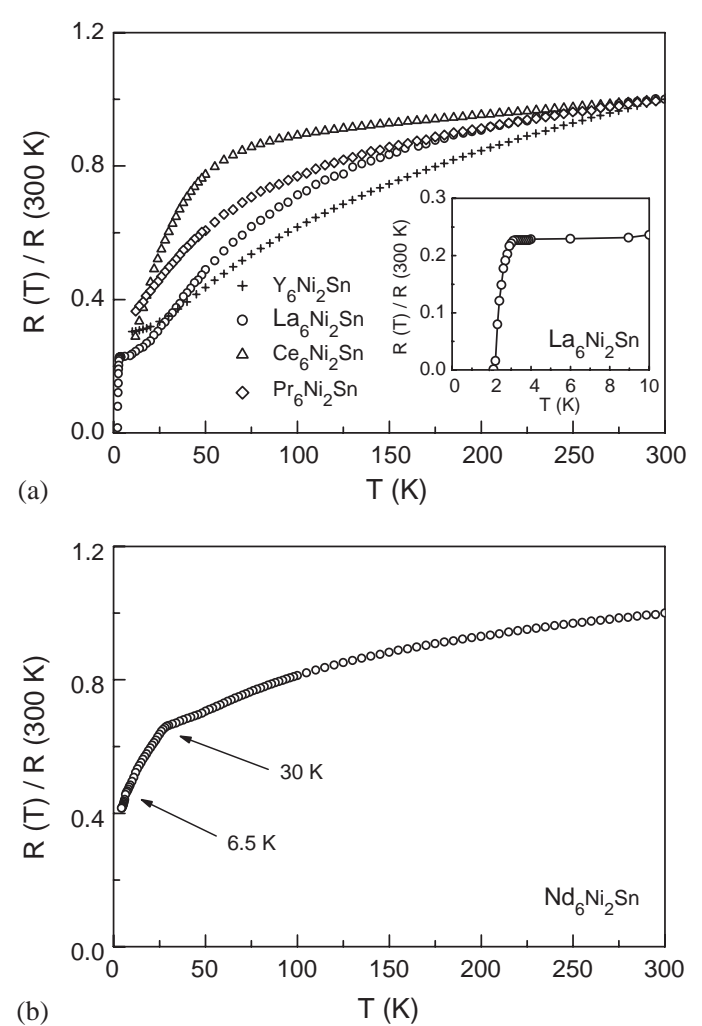

Fig. 1. (a) $R(T) / R(300 \mathrm{~K})$ curves for $\mathrm{R}_{6} \mathrm{Ni}_{2} \mathrm{Sn}(\mathrm{R}=\mathrm{Y}$. La, Ce, and Pr). (b) $R(T) / R(300 \mathrm{~K})$ curves for $\mathrm{Nd}_{6} \mathrm{Ni}_{2} \mathrm{Sn}$.

using a four-probe $\mathrm{AC}$ technique. DC magnetic susceptibility measurements were performed in a commercial superconducting quantum interference device (SQUID) magnetometer from 2 to $300 \mathrm{~K}$ in various applied magnetic fields. The specific heat of $\mathrm{Ce}_{6} \mathrm{Ni}_{2} \mathrm{Sn}$ was measured using in ${ }^{3} \mathrm{He}$ microcalorimeter in the temperature range between 0.35 and $20 \mathrm{~K}$ with $H=0$.

The normalized electrical resistance $R(T) / R(300 \mathrm{~K})$ vs. $T$ curves for the $\mathrm{R}_{6} \mathrm{Ni}_{2} \mathrm{Sn}$ $(\mathrm{R}=\mathrm{Y}, \mathrm{La}, \mathrm{Ce}$, and $\mathrm{Pr})$ compounds are plotted in Fig. 1(a) for $0 \mathrm{~K} \leqslant T \leqslant 300 \mathrm{~K}$. The $R(T) / R(300 \mathrm{~K})$ curves for these samples exhibit typical characteristics of common metal and decrease monotonically with decreasing temperature $T$. The abrupt drop of $R(T) / R(300 \mathrm{~K})$ to zero value, as shown in the inset, reveals that $\mathrm{La}_{6} \mathrm{Ni}_{2} \mathrm{Sn}$ becomes superconducting below $2.3 \mathrm{~K}$ [4]. Shown in Fig. 1(a) is the $R(T) / R(300 \mathrm{~K})$ curve for $\mathrm{Nd}_{6} \mathrm{Ni}_{2} \mathrm{Sn}$. A rapid drop at $30 \mathrm{~K}$ and a change of
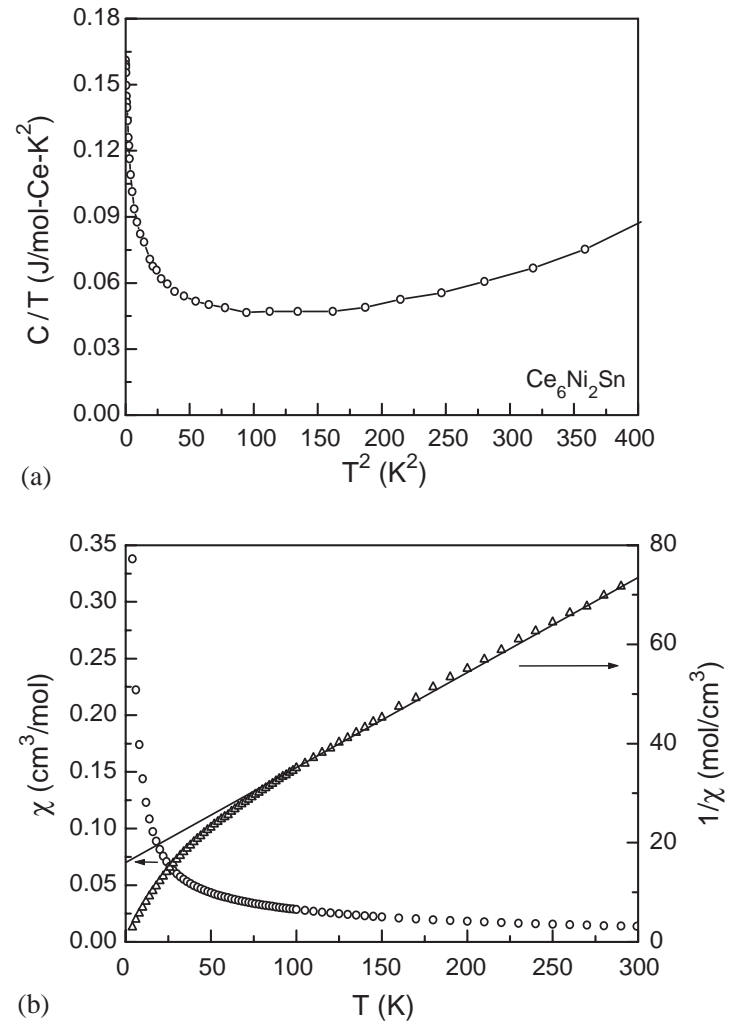

Fig. 2. (a) $C / T$ vs. $T^{2}$ and (b) $\chi(T)$ and $\chi^{-1}(T)$ curves for $\mathrm{Ce}_{6} \mathrm{Ni}_{2} \mathrm{Sn}$.

the slope at $6.5 \mathrm{~K}$ in the $R(T) / R(300 \mathrm{~K})$ curve indicates the occurrence of two magnetic transitions in this compound. This is consistent with the result of the magnetic susceptibility study which reveals that $\mathrm{Nd}_{6} \mathrm{Ni}_{2} \mathrm{Sn}$ undergoes antiferromagnetic transition at $29 \mathrm{~K}$ followed by an order-order transition at $6.2 \mathrm{~K}$. Various magnetic transitions at low temperatures were also observed in the $\mathrm{R}_{6} \mathrm{Ni}_{2} \mathrm{Sn}$ compounds with $\mathrm{R}=\mathrm{Sm}, \mathrm{Gd}, \mathrm{Tb}, \mathrm{Dy}$, and Ho [5].

The low-temperature specific heat of $\mathrm{Ce}_{6} \mathrm{Ni}_{2} \mathrm{Sn}$ is depicted in Fig. 2(a), where $C / T$ vs. $T^{2}$ are plotted. The specific behaviour for this compound reveals characteristics of heavy fermion compounds. A characteristic logarithmic divergence of $C / T$ data over the temperature range of $1 \mathrm{~K}<T<7 \mathrm{~K}$ indicates non-Fermi liquid behaviour in this compound. The obtained value of $C / T$ is $\sim 160 \mathrm{~mJ} / \mathrm{mol} \mathrm{Ce}-\mathrm{K}^{2}$ at $0.35 \mathrm{~K}$. The $\chi(T)$ 
and $\chi^{-1}(T)$ vs. $T$ curves for $\mathrm{Ce}_{6} \mathrm{Ni}_{2} \mathrm{Sn}$, as plotted in Fig. 2(b), reveal that this compound is nonmagnetic for $T>2 \mathrm{~K}$. Above $\sim 100 \mathrm{~K}$, the $\chi(T)$ curve follow a Curie-Weiss behaviour with a value of effective moment $\mu_{\text {eff }}=2.68 \mu_{\mathrm{B}}$.

In summary, we have studied the electrical, magnetic, and specific properties of the $\mathrm{R}_{6} \mathrm{Ni}_{2} \mathrm{Sn}$ compounds. We found that $\mathrm{La}_{6} \mathrm{Ni}_{2} \mathrm{Sn}$ becomes superconducting below $2.3 \mathrm{~K}$. Two magnetic transitions were observed in $\mathrm{Nd}_{6} \mathrm{Ni}_{2} \mathrm{Sn}$ at 30 and $6.5 \mathrm{~K}$, respectively.

We found that $\mathrm{Ce}_{6} \mathrm{Ni}_{2} \mathrm{Sn}$ is a non-magnetic heavy fermion system with an obtained value of $C /$ $T=160 \mathrm{~mJ} / \mathrm{mol} \mathrm{Ce}-\mathrm{K}^{2}$ at $0.35 \mathrm{~K}$.

This work was supported by the ROC National Science Council under Grant no. NSC 92-2112M002-031.

\section{References}

[1] O.M. Sichevich, L.P. Komarovskaya, Yu.N. Grin, Ya.P. Yarmolyuk, R.V. Skolozdra, Ukr. Fiz. J. 29 (1984) 1342 (in Ukrainian).

[2] K.A. Gschneidner Jr., V.K. Pecharsky, M. Gailloux, in: R.G. Ross Jr. (Ed.), Crycollers, vol. 8, Plenum Press, New York, 1995.

[3] O. Syshchenko, Yu. Stdnyk, L. Romaka, Yu. Mudryk, R.V. Dremov, V. Sechovsky, J. Alloy Comp. 319 (2001) 14.

[4] J.W. Chen, N.S. Jou, B.K. Wang, C.-R. Chang, R.C. Yang, Physica C 384 (2003) 71.

[5] J.W. Chen, et al., to be published. 